\title{
Research on Fiber Micro-Surfacing Mixture Design and Pavement Performance in Interchange's Connections
}

\author{
Zhaoyang $\mathrm{Wu}$ \\ Key Laboratory of Special Area Highway Engineering of Ministry of Education, \\ Highway School of Chang'an University, Xi'an, Shaanxi, China
}

\begin{abstract}
In order to use the micro-surfacing which is the existing micro-surfacing technology guide that has some technical defects, the method to determine the optimal dosage of emulsified asphalt and best whetstone is not very reasonable, and it impedes the application and development of micro-surfacing technology to improve the performance of the pavement. In this paper, the "graphical method" is first used to determine the optimal dosage range of emulsified asphalt. Nowadays, a large number of expressways reach the stage of repair and maintenance. Interchange ramp exit and entrance are always the accident-prone sections and, it's easy to overlook the pavement's skid resistance of those areas. Micro-surfacing can significantly improve the performance of pavement, especially the skid resistance. Verified with laboratory tests, it recommends that the dosage of emulsified asphalt corresponding to the peak of flexural strain measured with low temperature bending test as OAC of micro-surfacing mixture shows technical superiority. The use of fiber micro-surfacing at the ramp's exit and entrance can reduce the braking distance.
\end{abstract}

Keywords: interchange; ramp exit and entrance; fiber micro-surfacing mixture; best whetstone ratio; cold bending test.

\section{INTRODUCTION}

Nowadays, a large number of expressways need repair and maintenance. But it's easy to overlook the pavement's skid resistance of the interchange at ramp exit and entrance. So the use of micro-surfacing to improve the pavement skid resistance in this area and reduce the braking distance is important to decrease accidents in these areas. Recently, it has been found that the micro-surfacing did not achieve the desired goals. There exist many problems in roads paved with micro-surfacing, such as the poor resistance to crack and the bad performance for heavy traffic, which result in a shorter service life of micro-surfacing pavement. When filling thick ruts in practical application, micro-surfacing shows a lack of effective resistance to rutting deformation, which greatly limits the promotion and application of this technology in domestic preventive maintenance ${ }^{[1-3]}$.

It is well acknowledged that after adding fiber, micro-surfacing performance will be improved, but the current research is still relatively weak. There is a lack of systematic design on the fiber micro-surfacing mixture ratio design, the design index and other aspects. Therefore, it is necessary to carry out specialized research and ways to play the advantage of micro-surfacing technology in preventive maintenance and achieve a win-win situation of social and economic benefits.

\section{RAW MATERIALS TECHNICAL INDEX OF FIBER MICRO-SURFACING}

The main materials that Fiber Micro-surfacing Mix used are polymer modified asphalt emulsion, fiber, mineral aggregate, filler, water and additives. Their qualities directly affect the pavement performance of mixture ${ }^{[4,5]}$. Therefore, when choosing materials, their various technical indicators should meet the requirements of the corresponding specification.

\subsection{Modified emulsified asphalt}

Emulsified asphalt used in this study is SBR modified asphalt emulsion, which consists of AH-70 asphalt, slow-breaking-fast-setting type cationic emulsifier (MK-06 type), SBR latex, hydrochloric acid, water and stabilizer (PVA and chlorine calcium), and it is made by the modified and emulsified equipment. Its technical performance test results are shown in Table 1.

\subsection{Mineral aggregate}

At present, most of asphalt mixtures use limestone, basalt and diabase and so on. The basalt has good compression resistance, abrasion resistance, adhesion and other properties, so we choose two different lithological stones as mineral aggregate, two different basalts as coarse aggregate, and two different limestones as fine aggregate. The test results show that various technical indicators of mineral aggregate can meet the standard requirements ${ }^{[6]}$ 
MATEC Web of Conferences

Table 1. SBR modified asphalt emulsion test results and technical requirements

\begin{tabular}{|c|c|c|c|c|c|}
\hline \multicolumn{2}{|l|}{ Test Items } & Unit & $\begin{array}{l}\text { Standard Requirement } \\
(\mathrm{BCR})\end{array}$ & $\begin{array}{l}\text { Measured } \\
\text { Value }\end{array}$ & $\begin{array}{l}\text { Test } \\
\text { Method }\end{array}$ \\
\hline \multicolumn{2}{|l|}{ Residue on Sieve (1.18mm) } & $\%$ & $\leq 0.1$ & 0.02 & T0652 \\
\hline \multicolumn{2}{|l|}{ Charge } & & + & + & T0653 \\
\hline \multicolumn{2}{|c|}{ Asphalt Standard Viscosity $\mathrm{C}_{25.3}$} & $\mathrm{~s}$ & $12 \sim 60$ & 14.7 & T0621 \\
\hline \multicolumn{2}{|c|}{ Amount of Evaporation Residue } & $\%$ & $\geq 60$ & 63.3 & T0651 \\
\hline \multirow{4}{*}{$\begin{array}{l}\text { Properties of Evaporation } \\
\text { Residue }\end{array}$} & $\begin{array}{l}\text { Penetration } \\
\left(25^{\circ} \mathrm{C}, 5 \mathrm{~s}\right)\end{array}$ & $0.1 \mathrm{~mm}$ & $40 \sim 100$ & 66.8 & T0604 \\
\hline & Softening Point & ${ }^{\circ} \mathrm{C}$ & $\geq 53$ & 63.2 & T0606 \\
\hline & Ductility $\left(5^{\circ} \mathrm{C}\right)$ & $\mathrm{cm}$ & $\geq 20$ & $>100$ & T0605 \\
\hline & $\begin{array}{l}\text { Solubility } \\
\text { (Trichloroethylene) }\end{array}$ & $\%$ & $\geq 97.5$ & 99.8 & T0607 \\
\hline \multirow{2}{*}{ Storage Stability } & $1 \mathrm{~d}$ & $\%$ & $\leq 1$ & 0.4 & \multirow{2}{*}{ T0655 } \\
\hline & $5 \mathrm{~d}$ & $\%$ & $\leq 5$ & 3.2 & \\
\hline
\end{tabular}

Table 2. Polypropylene fiber performance indicators

\begin{tabular}{|l|l|l|l|}
\hline Test Items & Test Results & Test Items & Test Results \\
\hline Ingredients & polypropylene & Ultimate Elongation (\%) & $\geq 15$ \\
\hline Equivalent Diameter $(\mathrm{mm})$ & 0.02 & Elastic Modulous (Mpa) & $>3600$ \\
\hline Density $\left(\mathrm{g} / \mathrm{cm}^{3}\right)$ & 0.91 & Melting Point $\left({ }^{\circ} \mathrm{C}\right)$ & 160 \\
\hline Acid-alkali Resistance & very high & Tensile Strength (Mpa) & $>350$ \\
\hline Fiber Type & wispy monofilament & Thermal Conductivity & very low \\
\hline Safety & non-toxic, non-irritating & Ignition Point $\left({ }^{\circ} \mathrm{C}\right)$ & 580 \\
\hline Fiber Cross-section & circle & Specification $(\mathrm{mm})$ & 6 \\
\hline
\end{tabular}

Table 3. Micro-surfacing aggregate gradation

\begin{tabular}{|l|l|l|l|l|l|l|l|l|}
\hline \multirow{2}{*}{ Gradation Type } & \multicolumn{9}{l|}{ Percentage Passing the Sieve (\%) } \\
\cline { 2 - 10 } & 9.5 & 4.75 & 2.36 & 1.18 & 0.6 & 0.3 & 0.15 & 0.075 \\
\hline Requirement & 100 & $70-90$ & $45-70$ & $28-50$ & $19-34$ & $12-25$ & $7-18$ & $5-15$ \\
\hline Median value of MS-3 & 100 & 80 & 57.5 & 39 & 26.5 & 18.5 & 12.5 & 10 \\
\hline
\end{tabular}

\subsection{Fiber}

After adding fibers, the mechanical properties of asphalt mixture can be significantly improved. The micro-surfacing adopts KWS-A3 polypropylene fiber due to its good low-temperature performance, low prices and wide application, and its main performance indicators are shown in Table 2.

\subsection{Water}

Water in the micro-surfacing consists of three parts, namely, the water in the mineral aggregate, emulsion, and the additional water, accounting for about $6 \%-11 \%$ of dried mineral aggregate quality. In view of this, we must control the amount of additional water strictly, which is the key to assure the consistency and paving effect of the micro-surfacing.

\subsection{Filler}

This paper adopts the P. O grade 325 ordinary Portland cement, limestone and mineral powder as filler. After tested, various technical indicators of filler can meet standard requirements.

\section{FIBER MICRO-SURFACING MIX DESIGN}

\subsection{Determination of mineral aggregate gradation}

Domestic micro-surfacing mineral aggregate gradation range was formulated according to the relevant provisions of International Slurry Surfacing Association 
EMME 2015

Table 4. Mixing test results (Temperature: $25^{\circ} \mathrm{C}$ )

\begin{tabular}{|c|c|c|c|c|c|}
\hline Fiber Content (\%) & Aggregate (g) & Additional Water (g) & Cement (\%) & Mixing Time (s) & Requirement (s) \\
\hline \multirow{3}{*}{0.05} & 200 & 13 & 1.5 & 139 & \multirow{15}{*}{$\geq 120$} \\
\hline & 200 & 14 & 2.0 & 135 & \\
\hline & 200 & 15 & 2.5 & 130 & \\
\hline \multirow{3}{*}{0.1} & 200 & 15 & 1.5 & 132 & \\
\hline & 200 & 16 & 2.0 & 127 & \\
\hline & 200 & 17 & 2.5 & 125 & \\
\hline \multirow{3}{*}{0.15} & 200 & 16 & 1.5 & 127 & \\
\hline & 200 & 17 & 2.0 & 125 & \\
\hline & 200 & 17 & 2.5 & 122 & \\
\hline \multirow{3}{*}{0.20} & 200 & 15 & 1.5 & 135 & \\
\hline & 200 & 15 & 2.0 & 127 & \\
\hline & 200 & 16 & 2.5 & 122 & \\
\hline \multirow{3}{*}{0.25} & 200 & 15 & 1.5 & 138 & \\
\hline & 200 & 16 & 2.0 & 127 & \\
\hline & 200 & 17 & 2.5 & 124 & \\
\hline
\end{tabular}

Table 5. Results of wet track abrasion test and load wheel test

\begin{tabular}{|l|l|l|l|}
\hline $\begin{array}{l}\text { Asphalt-aggregate ratio } \\
(\%)\end{array}$ & $\begin{array}{l}\text { Wet-track abrasion loss of } 1 \mathrm{~h} \\
\left(\mathrm{~g} / \mathrm{m}^{2}\right)\end{array}$ & $\begin{array}{l}\text { Wet-track abrasion loss of 6d } \\
\left(\mathrm{g} / \mathrm{m}^{2}\right)\end{array}$ & $\begin{array}{l}\text { Sand adhesion amount } \\
\left(\mathrm{g} / \mathrm{m}^{2}\right)\end{array}$ \\
\hline 6.0 & 645.3 & 835.7 & 317.6 \\
\hline 6.5 & 526.5 & 789.3 & 367.3 \\
\hline 7.0 & 429.4 & 673.0 & 392.9 \\
\hline 7.5 & 342.8 & 557.2 & 403.5 \\
\hline 8.0 & 238.3 & 524.5 & 437.3 \\
\hline
\end{tabular}

(ISSA) by Research Institute of Highway Ministry of Transport in 2004. According to the mineral aggregate gradation, gradation can be divided into MS-2 and MS-3. The most common gradation type used in the micro-surfacing project in China is MS-3, while MS-2 is seldom used ${ }^{[8]}$. In combination with the practical situation of project, this paper adopts MS-3 type for research. The tested gradation is shown in Table 3.

\subsection{Mixing test on determining the amount of cement and mixing water}

Mixing test is mainly used to determine the mixing time and slurred state of the micro-surfacing mix, so as to provide the basis for the choice of the optimal asphalt-aggregate ratio. In order to assess the effect of adding fiber on the amount of additional water, we choose the asphalt-aggregate ratio of $7.5 \%$ and differ- ent fiber dosage to conduct the mixing test. The test results are shown in Table 4.

Table 4 shows the test results:

(1) When the fiber dosage is in the range of 0 to 0.1 percent, the additional water consumption increases with the increase of fiber dosage. However, after the fiber dosage exceeds 0.1 percent, additional water consumption tends to be stable.

(2) Mixing water consumption increases with the increase of cement dosage. When the cement dosage is 2 percent, the mixing time is most appropriate.

In conclusion, combined with estimative engineering experience, materials ratio was preliminarily confirmed: The ratios of polyester fiber dosage, cement dosage, mixing water consumption and total fluid content (the sum of the emulsified asphalt dosage and the mixing water consumption) are respectively $0.2 \%$, $2 \%, 8 \%$ and $15.5 \%$. 
MATEC Web of Conferences

Table 6 . Results of stability and resistance to compaction test and cohesion torque test

\begin{tabular}{|l|l|l|l|}
\hline $\begin{array}{l}\text { Asphalt-aggregate ratio } \\
(\%)\end{array}$ & $\begin{array}{l}\text { Cohesion torque of 30min } \\
(\mathrm{N} . \mathrm{m})\end{array}$ & $\begin{array}{l}\text { Cohesion torque of 60min } \\
(\mathrm{N} . \mathrm{m})\end{array}$ & $\begin{array}{l}\text { Rate of width change } \\
(\%)\end{array}$ \\
\hline 6.0 & 1.21 & 2.1 & 4.1 \\
\hline 6.5 & 1.24 & 2.4 & 3.4 \\
\hline 7.0 & 1.27 & 2.4 & 3.1 \\
\hline 7.5 & 1.30 & 2.3 & 3.4 \\
\hline 8.0 & 1.29 & 2.4 & 4.0 \\
\hline
\end{tabular}

Table 7. Low temperature flexural creep test results of fiber micro-surfacing mix

\begin{tabular}{|l|l|l|l|}
\hline $\begin{array}{l}\text { Asphalt aggregate } \\
\text { ratio }\end{array}$ & $\begin{array}{l}\text { Flexural tensile strength } \\
(\mathrm{MPa})\end{array}$ & $\begin{array}{l}\text { Maximum flexural tensile strain } \\
(\mu \varepsilon)\end{array}$ & $\begin{array}{l}\text { Bending stiffness modulus } \\
(\mathrm{MPa})\end{array}$ \\
\hline 6.5 & 6.78 & 2812.64 & 2410.55 \\
\hline 7.0 & 7.10 & 3067.32 & 2314.72 \\
\hline 7.5 & 7.37 & 3031.30 & 2431.30 \\
\hline 8.0 & 7.22 & 2833.02 & 2548.52 \\
\hline
\end{tabular}

3.3 Determination of the optimal dosage range of emulsified asphalt

Keep the cement content of $2 \%$ and fiber content of $0.5 \%$ fixed respectively. Regarding the predicted optimum emulsified asphalt content $7 \%$ as median, change the emulsified asphalt content by interval $0.5 \%$. In order to ensure the total fluid content remains the same, change the corresponding mixing water while changing the emulsified asphalt content. The wet track abrasion test, the load wheel test, the stability and resistance to compaction test and the cohesion torque test were done to determine the optimal asphalt-aggregate ratio range of fiber micro-surfacing mixture ${ }^{[9]}$. The test results are shown in Table 5 and Table 6.

The test result in Table 5 and Table 6 shows that the asphalt-aggregate ratio within the range of $6.5 \%-8 \%$ can meet the specification requirements.

\subsection{Determination of optimal dosage of emulsified asphalt based on bending test of small beam}

This paper is within the scope of optimal asphalt-aggregate ratio which is determined by the conventional test method, and by introducing the bending test of small beam to accurately calculate the optimal asphalt-aggregate ratio of micro-surfacing mixture.

The combination of the range of optimal asphalt-aggregate ratio is determined by graphical method, and the preliminary emulsified asphalt content for small beam test is respectively $6.5 \%, 7 \%, 7.5 \%$ and $8 \%$. Mixing the fiber, cement and mineral powder evenly; then adding appropriate water; next, adding predetermined quality of modified emulsified asphalt after mixing evenly; at last, mixing them evenly for use. The test results are shown in Table 7.

From Table 8, as the increase of asphalt-aggregate ratio, although the maximum flexural tensile strain of fiber micro-surfacing mix has little difference, there is still an obvious change rule. The maximum flexural tensile strain of $-10^{\circ} \mathrm{C}$ shows a parabolic trend (which increases at first and then decreases) with the increase of asphalt-aggregate ratio. When asphalt-aggregate ratio is about $7.7 \%$, the maximum flexural tensile strain has a maximum value.

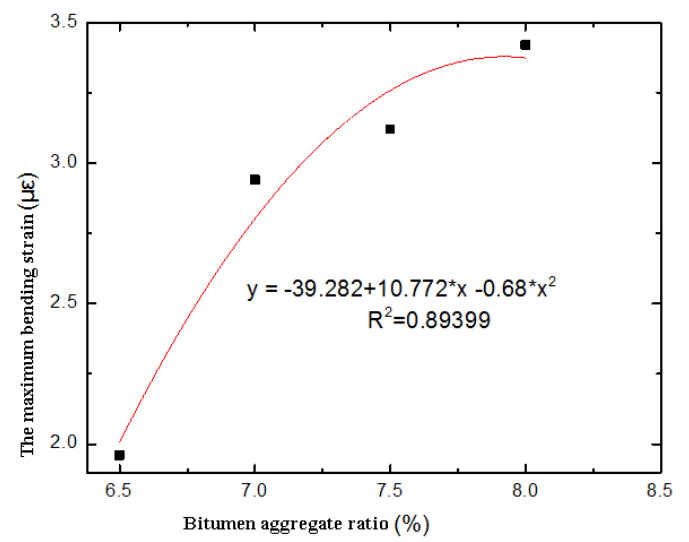

Figure 1. Flexural tensile strain variation with asphalt-aggregate ratio

In summary, the fiber micro-surfacing mix optimal asphalt-aggregate ratio is $7.7 \%$; the cement content is $2 \%$; the optimal fluid content is $15.5 \%$ (the mixing water consumption is $6.8 \%$ ); the dosage of fiber is $0.2 \%$. 
EMME 2015

Table 8. Results of construction performance test

\begin{tabular}{|c|c|c|c|c|}
\hline \multirow{2}{*}{ Type of micro-surfacing } & \multicolumn{4}{|c|}{ Value of Cohesion Torque $(\mathrm{N} \cdot \mathrm{m})$} \\
\hline & $30 \mathrm{~min}$ & Specimen State & $60 \mathrm{~min}$ & Specimen State \\
\hline \multirow{8}{*}{ Polypropylene Fiber Micro-surfacing } & 1.35 & Broken & 2.36 & Medium Molding \\
\hline & \multicolumn{4}{|c|}{ Wet-track Abrasion Loss } \\
\hline & $1 \mathrm{~h}$ & Requirements & $6 \mathrm{~d}$ & Requirements \\
\hline & 320.5 & $\leq 540 \mathrm{~g} / \mathrm{m}^{2}$ & 530.1 & $\leq 800 \mathrm{~g} / \mathrm{m}^{2}$ \\
\hline & \multicolumn{4}{|c|}{ Lateral Displacement } \\
\hline & Measured Value & $3.2 \%$ & Requirements & $\leq 5 \%$ \\
\hline & \multicolumn{4}{|c|}{ Excess Asphalt by LWT Sand Adhesion } \\
\hline & Measured Value & $410 \mathrm{~g} / \mathrm{m}^{2}$ & Requirements & $\leq 800 \mathrm{~g} / \mathrm{m}^{2}$ \\
\hline
\end{tabular}

Table 9. Thaw splitting test results

\begin{tabular}{|l|l|l|l|}
\hline Asphalt aggregate ratio $(\%)$ & $\mathrm{R}_{\mathrm{T} 1}(\mathrm{MPa})$ & $\mathrm{R}_{\mathrm{T} 2}(\mathrm{MPa})$ & $\mathrm{TSR}(\%)$ \\
\hline 6.5 & 0.754 & 0.624 & 82.7 \\
\hline 7.0 & 0.815 & 0.662 & 81.27 \\
\hline 7.5 & 0.903 & 0.782 & 86.6 \\
\hline 7.7 & 0.912 & 0.783 & 85.9 \\
\hline 8.0 & 0.920 & 0.749 & 81.4 \\
\hline
\end{tabular}

4 RATIONALITY VERIFICATION OF OPTIMAL DOSAGE OF EMULSIFIED ASPHALT

In this paper, in order to verify the rationality and applicability of the method for determining the optimal dosage of emulsified asphalt, the indoor simulation experiment is carried out.

\subsection{Verification of construction performance}

The initial set time and traffic time of micro-surfacing are mainly evaluated by the cohesion torque test, and the value of which has great influence on whether the micro-surfacing can meet the requirements of quick traffic. When undertaking verification of construction performance, and in the fiber micro-surfacing mix, the cement content is $2 \%$, the fluid content is $15.5 \%$, the dosage of fiber is $0.2 \%$, and the emulsified asphalt content is $7.7 \%$.

From the data listed in Table 8, the optimal dosage of emulsified asphalt determined by the peak of flexural tensile strain can meet the requirements of micro-surfacing mix in quick traffic.

\subsection{Verification of pavement performance}

1. MMLS3 Accelerated loading test

Refer to the research results of Shen Aiqin [11-14] test conditions of MMLS3 in this paper are the same.

Load times. The MMLS3 accelerated loading equipment can test and record each scene specimen's rutting depth, and then the variation between the changes of each scene specimen with axle load times can be obtained (Figure 2).

It can be found when comparing the load times of entering the destruction phase that the joining fiber can apparently improve the resistance to permanent deformation of micro-surfacing mixture with the same asphalt aggregate ratio and the fatigue life of micro-surfacing mixture under the high temperature condition.

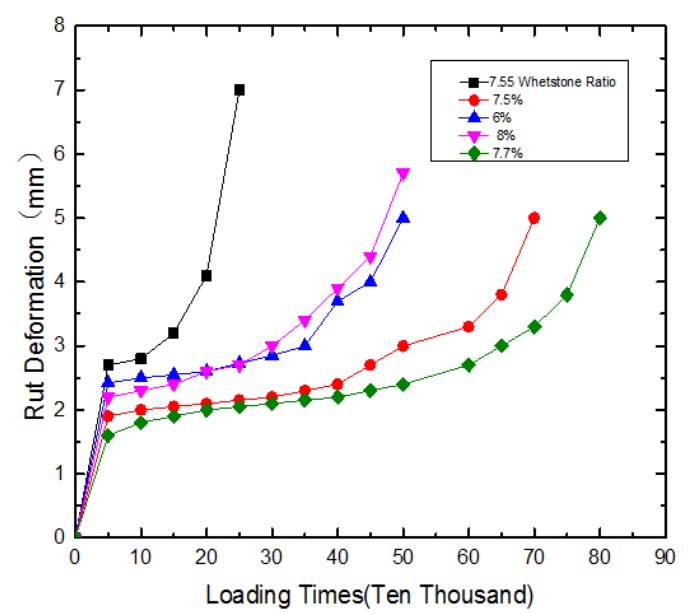

Figure 2. Accelerated loading test results

\section{Freeze-thaw splitting test}

The water stability of asphalt mixture is usually evaluated by freeze-thaw splitting test ${ }^{[15,16]}$. The ratio 


\section{MATEC Web of Conferences}

of average of splitting strength can be regarded as evaluation index ${ }^{[10]}$. The results of test are shown in Table 9.

It can be concluded from the test results that the fiber micro-surfacing mixture's freeze-thaw splitting strength over the code value is more than $80 \%$ when the emulsified asphalt content accounting for 7.7 percent.

\section{SUPERIORITY OF CONFIRMING THE BEST} EMULSIFIED ASPHALT CONTENT BY THE LOW TEMPERATURE BENDING TEST

Compared with the "graphical method", this paper uses the maximum value to confirm the best emulsified asphalt content. It has many advantages as follows:

(1) When confirming the best emulsified asphalt content by the "graphical method" that is stipulated by standard, it needs 4-5 asphalt aggregate ratios to prepare samples, and then to confirm a range of asphalt aggregate ratio by conducting wet-wheel abrasion test and grinding wheel load test. But in fact, the range confirmed by this way is large and extensive, and it's also difficult to confirm an accurate asphalt aggregate ratio and usually determined by engineering experience in practical engineering application. The method which is mentioned in this paper confirms the best emulsified asphalt content of fiber micro-surfacing mixture on the basis of the low temperature bending test and "graphical method" and can directly give an accurate number value and reduces the dependency on the design experience when designing mix proportion of fiber micro-surfacing mixture.

(2) The "graphical method" can not only confirm the best emulsified asphalt content, but also take low temperature cracking resistance into consideration. It is essentially a dual-index design method.

(3) The dramatic inner temperature stress is on the micro-surfacing, which directly bears the external temperature as the surface layer of pavement. In order to improve the low temperature crack resistance, the low temperature performance of mixture should be verified on the mix proportion design stage. It is beneficial to improve the pavement performance of fiber micro-surfacing mixture that the low temperature crack resistance indicator is used in design.

(4) The low temperature bending test is easy to get the evaluation indicator with the normal testing procedures.

\section{CONCLUSIONS}

The test results showed that the optimum asphalt-aggregate ratio of micro-surfacing was determined with the peak value of flexural tensile strain on the range of graphic method results to improve the pavement performance.

Combined with the result and the design experience, the track plate specimens with 4 asphalt-aggregate ratios which are in the range of graphic method $\mathrm{P}_{\mathrm{bmin}}-\mathrm{P}_{\mathrm{bmax}}$ were cured for 2 days at $60^{\circ} \mathrm{C}$ and then were cut into small beams, namely, beams which are $250 \mathrm{~mm} \times 30 \mathrm{~mm} \times 35 \mathrm{~mm}$. The asphalt-aggregate ratio was determined by the $-10^{\circ} \mathrm{C}$ low-temperature bending test with the beam cracking resistance indicator.

\section{REFERENCES}

[1] Li Shuan, Wang Mingming, \& Dong Jiangtao. 2008. Communication Standard.

[2] Liu Weiliang. 2011. Research on Mixture Performance and Application Technology of Micro-surfacing -Chang'an University.

[3] Ju Hao, \& Huang Xiaoming. 2007. Highway.

[4] Zhang Jie, Cheng Xianghua, \& Zhang Xiaoning, 2009. Maintenance Machinery \& Construction Technology.

[5] Sun Xiaoli, \& Zhang Xiaoning, 2012. Journal of Tongji University (Natural Science).

[6] JTG F40-2004 Technical Specifications for Construction of Highway Asphalt Pavements. Beijing: China Communications Press (2004).

[7] Liu Zhisheng, Li Miaoguo, \& Kou Enlong, 2008. Petroleum Asphalt.

[8] Technical Guidelines for Micro-Surfacing and Slurry Seal. Beijing: Research Institute of Highway Ministry of Transport, China Communications Press (2006)

[9] JTG E20-2011. 2011. The Test Criterion for Highway Project Pitch and Pitch Compounds. Beijing: China Communications Press.

[10] Shen Aiqin. 2012. China Journal of Highway and Transport.

[11] Sun Xiaoli, Zhang Xiaoning, \& Cai Xu, 2012. Journal of Tongii University (Natural Science).

[12]Lu Hewei, Zhang Hongchao, Wang Jian, \& Guo Yinan, 2011. Journal of Building Materials.

[13]Zhao Qianqian. 2013. North Transportation.

[14]Zheng Xuejun. 2001. Road Subgrade and Pavement Engineering. Beijing: China Communications Press

[15] Sun Lijun. 2003. Structural Behavior Study for Asphalt Pavements. Shanghai: Tongji University Press. 